\title{
ANALISIS MODEL ANTRIAN MULTIPLE CHANNEL MULTIPLE PHASE SERVICE DALAM PROSES PEMBUATAN KARTU MAHASISWA (KTM) PADA BANK BNI UNTAD
}

\author{
R. Usman ${ }^{1}$, A. I. Jaya², dan D. Lusiyanti ${ }^{3}$ \\ 1,2,3Program Studi Matematika Jurusan Matematika FMIPA Universitas Tadulako \\ Jalan Soekarno-Hatta Km. 09 Tondo, Palu 94118, Indonesia. \\ 1rachmatpares@gmail.com, 2agusindrajaya@yahoo.com, 3desylusiyanti@yahoo.com.
}

\begin{abstract}
The queue is a common situation that is common in our daily lives as consumers waited in front of the booth to get a turn to the service or service facilities. One example is the manufacture queue Student Identity Card (KTM) Tadulako in Bank BNI UNTAD. The purposes of this research is to analyze the characteristics of the making of queue Student Identity Card (KTM) Tadulako in Bank BNI of UNTAD. By calculating the probability were no queues $\left(P_{0}\right)$,the average customer in the queue $\left(L_{a}\right)$,the average customer in the system $\left(L_{s}\right)$,the average waiting time for customers in the queue $\left(\mathrm{W}_{\mathrm{a}}\right)$,the average time waiting for customers in the system $\left(\mathrm{W}_{s}\right)$. The results showed that the model type of queue that is used in the manufacture of Student Card (KTM) Tadulako in Bank BNI UNTAD is a model of multiple channels-multiple phase $(M / M / S)$ with a Poisson arrival pattern distribution and exponential distribution service time. The analysis shows the performance characteristics of a queuing system manufacture KTM BANK BNI of UNTAD can be said to have been effective, because of the steady state in each stage. On Wednesday, the value of $\left(P_{0}\right)$ at CS is 0,145 and the teller is 0.8879 ,for the value of $\left(L_{a}\right)$ in CS is 1.8821 and the teller customer is a customer 0.0004 tothe value $\left(L_{s}\right) 3.4948$ is the customer, to the value of $\left(\mathrm{W}_{\mathrm{a}}\right)$ on CS is 33.5373 minutes and the teller was 0.0075 minutes, to the value of $\left(\mathrm{W}_{s}\right)$ is 74.1952 minutes. On Thursday, the value of $\left(P_{0}\right)$ on CS was 0.121 and the teller is 0.8837 ,for the value of $\left(L_{a}\right)$ in CS is 2.4998 and the teller customer is a customer 0.0005 tothe value $\left(L_{s}\right) 4.1918$ is the customer, to the value of $\left(\mathrm{W}_{\mathrm{a}}\right)$ on CS is 42.4061 minutes and the teller was 0.0081 minutes, to the value of $\left(\mathrm{W}_{s}\right)$ is 71.1808 minutes.
\end{abstract}

Keywords : : Exponential Distribution, Poisson Distribution, Queue Multi Phase

\section{ABSTRAK}

Antrian adalah suatu situasi umum yang biasa terjadi dalam kehidupan sehari-hari dimana konsumen menunggu di depan loket untuk mendapatkan giliran pelayanan atau fasilitas layanan. Salah satu contohnya adalah pembuatan Kartu Tanda Mahasiswa (KTM) Universitas Tadulako di Bank BNI UNTAD. Tujuan dalam penelitian ini adalah menganalisa karakteristik antrian pembuatan Kartu Tanda Mahasiswa (KTM) Universitas Tadulako di Bank BNI UNTAD. Dengan menghitung peluang tidak ada antrian $\left(P_{0}\right)$, rata-rata pelanggan dalam antrian $\left(L_{a}\right)$, rata-rata pelanggan dalam sistem $\left(L_{s}\right)$, rata-rata waktu menunggu pelanggan dalam antrian $\left(W_{a}\right)$, rata-rata waktu menunggu dalam sistem $\left(W_{s}\right)$. Hasil penilitian menunjukkan bahwa model jenis antrian yang digunakan pada pembuataan Kartu Tanda Mahasiswa (KTM) Universitas Tadulako di Bank BNI UNTAD adalah model multiple channel-multiple phase $(M / M / S)$ dengan pola kedatangan berdistribusi Poisson dan waktu pelayanan berdistribusi Eksponensial. 
Analisis karakteristik antrian menunjukkan kinerja sistem antrian pembuatan KTM di Bank BNI UNTAD dapat dikatakan sudah efektif, karena steady state di setiap tahap. Pada hari rabu nilai $P_{0}$ pada CS adalah 0,145 dan pada teller adalah 0,8879 , untuk nilai $L_{a}$ pada CS adalah 1,8821 pelanggan dan pada teller adalah 0,0004 pelanggan untuk nilai $L_{s}$ adalah 3,4948 pelanggan, untuk nilai $\mathrm{W}_{\mathrm{a}}$ pada CS adalah 33,5373 menit dan pada teller adalah 0,0075 menit, untuk nilai $\mathrm{W}_{s}$ adalah 74,1952 menit. Pada hari kamis nilai $P_{0}$ pada CS adalah 0,121 dan pada teller adalah 0,8837, untuk nilai $L_{a}$ pada CS adalah 2,4998 pelanggan dan pada teller adalah 0,0005 pelanggan untuk nilai $L_{s}$ adalah 4,1918 pelanggan, untuk nilai $\mathrm{W}_{\mathrm{a}}$ pada CS adalah 42,4061 menit dan pada teller adalah 0,0081 menit, untuk nilai $\mathrm{W}_{s}$ adalah 71,1808 menit.

\section{Kata Kunci : Distribusi Eksponensial, Distribusi Poisson, Antrian Multi Phase}

\section{PEDAHULUAN}

\subsection{Latar Belakang}

Di era modern seperti sekarang ini kecepatan dan penghematan waktu menjadi salah satu kebutuhan utama dalam menunjang segala kegiatan manusia. Kebutuhan akan kecepatan pelayanan jasa sangat diperlukan manusia dalam segala kegiatan terutama dalam hal penghematan waktu.

Salah satu permasalahan dalam kehidupan manusia yaitu masalah permintaan. Sering kita melihat banyak orang menunggu di suatu tempat fasilitas pelayanan umum, misalnya pada aktifitas pembuatan Kartu Tanda Mahasiswa (KTM) Universitas Tadulako. Umumnya setiap orang pernah mengalami antrian di dalam hidupnya. Oleh karena itu, bisa dikatakan bahwa antrian sudah menjadi bagian dari kehidupan setiap orang.

Universitas Tadulako adalah salah satu universitas negeri di Indonesia yang didirikan pada tanggal 14 Agustus 1981 sesuai dengan kepres no.36 tahun 1981 dengan jumlah mahasiswa aktif sebanyak 13.000 mahasiswa. kartu identitas yang mengukuhkan pencatatan resmi seseorang sebagai mahasiswa Universitas Tadulako adalah KTM yang diterbitkan oleh Bank Negara Indonesia (BNI). KTM Universitas Tadulako dipaketkan dengan rekening tabungan BNI. Pembuatan KTM Universitas Tadulako seringkali terkendala karena panjangnya antrian pembuatan KTM sehingga terjadinya penundaaan dan larinya mahasiswa yang bersangkutan dalam proses pembuatan KTM.

Antrian adalah suatu kejadian yang biasa dalam kehidupan sehari-hari. Menunggu di depan loket untuk mendapatkan tiket kereta api atau tiket bioskop, pada pintu jalan tol, pada bank, pada kasir supermarket, pada tempat pencucian mobil, dan situasi-situasi yang lain merupakan kejadian yang sering ditemui.

Antrian timbul disebabkan oleh kebutuhan akan layanan melebihi kemampuan (kapasitas) pelayanan atau fasilitas layanan, sehingga pengguna fasilitas yang baru tiba tidak bisa dengan segera mendapatkan layanan disebabkan kesibukan dari layanan tersebut. Pada 
banyak hal, tambahan fasilitas pelayanan dapat diberikan untuk mengurangi antrian atau untuk mencegah timbulnya antrian. Akan tetapi biaya karena memberikan pelayanan tambahan, akan menimbulkan pengurangan keuntungan mungkin sampai di bawah tingkat yang dapat diterima. Sebaliknya, sering timbulnya antrian yang panjang akan mengakibatkan hilangnya pelanggan/nasabah. Oleh karena itu, diperlukan kajian lebih dalam terkait dengan masalah antrian ini sebagai bahan pertimbangan bagi perusahaan dalam menentukan kebijakan yang diambil sehingga dapat memberikan pelayanan yang terbaik kepada pelanggan.

Permasalahan yang dihadapi adalah bagaimana mengusahakan keseimbangan antara biaya tunggu (antrian) terhadap biaya mencegah antrian, guna memberikan pelayanan yang optimal. Salah satu cara untuk memperbaiki fasilitas pelayanan dengan optimal adalah dengan menggunakan analisa Teori Antrian. Dengan analisa Teori Antrian dapat diketahui apakah sistem pelayanan yang ada sudah mencapai suatu keadaan yang optimal atau belum. Model antrian yang akan dibahas merupakan suatu metode yang penting untuk sistem pengolahan yang mengoptimalakan pelayanan dengan meminimalkan antrian. Pada model ini karakteristik sistem antrian antara lain meliputi: tingkat kesibukan server, jumlah rata-rata dalam antrian dan sistem untuk setiap pelayanan, probablitas antrian pada tahap pelayanan, rata-rata waktu menunggu dalam sistem dan antrian untuk setiap tahap pelayanan.

Pada proses antrian pembuatan KTM terjadi jenis antrian Multiple Channel Multiple Phase Service. Pada model antrian ini, terdapat lebih dari satu jalur pelayanan dan lebih dari satu fase pelayanan. Oleh karena itu, penulis tertarik untuk mengkaji lebih jauh mengenai beberapa parameter yang mempengaruhi kinerja dari sistem antrian pada proses pembuatan KTM.

\subsection{Rumusan Masalah}

Adapun rumusan masalah dalam penelitian ini adalah sebagai berikut:

1. Bagaimana model sistem antrian pada proses pembuatan KTM pada Bank BNI UNTAD?

2. Bagaimana hasil analisis dan solusi dari sistem antrian pada proses pembuatan KTM?

\subsection{Batasan Penelitian}

Adapun batasan dalam penelitian ini adalah untuk pengumpulan data dilakukan selama 2 hari, yaitu pada hari rabu dan kamis, dikarenakan pada hari tersebut mengikuti sistem antrian Multi Channel-Multi Phase. Pengambilan data hanya dilakukan selama 4 jam dalam sehari, yaitu dari jam 8pagi sampai jam 12 siang . 


\section{METODE PENELITIAN}

Penelitian ini dilakukan sesuai prosedur di bawah ini:

a. Mempersiapkan penelitian.

b. Mengkaji literatur tentang teori antrian, model antrian, distribusi eksponensial dan distribusi poisson

c. Mengumpulkan data dengan teknik wawancara dan observasi di Bank BNI cabang UNTAD.

d. Merumuskan model antrian

e. Menguji data tentang antrian yang terjadi pad tingkat kedatangan menggunakan distribusi poisson dan tingkat pelayanan menggunakan distribusi eksponensial.

f. Menguji data dengan menggunakan program WinQSB sebagai hasil perbandingan dengan hasil secara manual.

g. Menarik kesimpulan dari hasil penelitian.

III. HASIL DAN PEMBAHASAN

\subsection{Pengumpulan Data}

Penelitian ini menggunakan data primer yang berasal dari observasi dan wawancara singkat pada sistem pembuatan KTM UNTAD di Bank BNI cabang UNTAD. Data yang dikumplkan dalam penelitian ini adalah waktu kedatangan dan waktu pelayanan pada proses pembuatan KTM yang meliputi 2 fase pelayanan dan 2 server pada masing-masing fase

\subsection{Uji Kolmogorov Smirnov Menggunakan SPSS}

Tabel 1 : Data antrian pada hari rabu

\begin{tabular}{|c|c|c|c|c|}
\hline \multirow{2}{*}{ waktu kedatangan } & \multicolumn{2}{|c|}{ pelayanan di CS } & \multicolumn{2}{c|}{ pelayanan di Teller } \\
\cline { 2 - 5 } & mulai & selesai & mulai & selesai \\
\hline $8: 18$ & $8: 23$ & $8: 39$ & $8: 40$ & $8: 41$ \\
\hline $8: 21$ & $8: 26$ & $8: 51$ & $8: 52$ & $8: 54$ \\
\hline $8: 23$ & $8: 44$ & $9: 16$ & $9: 17$ & $9: 20$ \\
\hline $8: 40$ & $8: 57$ & $9: 24$ & $9: 25$ & $9: 28$ \\
\hline $9: 06$ & $9: 24$ & $9: 46$ & $9: 47$ & $9: 49$ \\
\hline $9: 12$ & $9: 30$ & $10: 02$ & $10: 03$ & $10: 05$ \\
\hline $9: 23$ & $9: 58$ & $10: 26$ & $10: 27$ & $10: 28$ \\
\hline $9: 27$ & $10: 12$ & $10: 40$ & $10: 41$ & $10: 43$ \\
\hline $10: 03$ & $10: 49$ & $11: 17$ & $11: 18$ & $11: 21$ \\
\hline
\end{tabular}

Tabel 2 : Data antrian hari kamis

\begin{tabular}{|c|c|c|c|c|}
\hline \multirow{2}{*}{ Waktu Kedatangan } & \multicolumn{2}{|c|}{ Pelayanan di CS } & \multicolumn{2}{c|}{ Pelayanan di Teller } \\
\cline { 2 - 5 } & Mulai & Selesai & Mulai & Selesai \\
\hline $8: 16$ & $8: 25$ & $8: 41$ & $8: 42$ & $8: 43$ \\
\hline
\end{tabular}




\begin{tabular}{|c|c|c|c|c|}
\hline $8: 30$ & $8: 32$ & $8: 55$ & $8: 56$ & $8: 58$ \\
\hline $8: 30$ & $8: 48$ & $9: 18$ & $9: 19$ & $9: 22$ \\
\hline $8: 40$ & $9: 02$ & $9: 35$ & $9: 36$ & $9: 38$ \\
\hline $8: 40$ & $9: 25$ & $9: 53$ & $9: 54$ & $9: 56$ \\
\hline $9: 00$ & $9: 46$ & $10: 13$ & $10: 14$ & $10: 16$ \\
\hline $9: 00$ & $9: 57$ & $10: 27$ & $10: 28$ & $10: 31$ \\
\hline $9: 28$ & $10: 25$ & $10: 45$ & $10: 47$ & $10: 49$ \\
\hline $10: 02$ & $10: 38$ & $11: 09$ & $11: 10$ & $11: 11$ \\
\hline $10: 27$ & $10: 59$ & $11: 29$ & $11: 30$ & $11: 33$ \\
\hline & & & & \\
\hline
\end{tabular}

Data pada Tabel 1 dan Tabel 2 dianalisis dengan menggunakan uji kolmogorov Smirnov satu sampel, dengan tujuan untuk menaksir nilai tingkat kedatangan $(\lambda)$ berdistribusi poisson dan nilai tingkat pelayanan $(\mu)$ berdistribusi eksponensial. Hasil pengujian distribusi data tingkat kedatangan dan data tingkat pelayanan ditunjukkan pada Tabel 3 dan Tabel 4.

Tabel 3 : Penggujian Distribusi Poisson pada Tingkat Kedatangan di CS dan Teller

One-Sample Kolmogorov-Smirnov Test

\begin{tabular}{|ll|r|r|r|r|}
\hline & & $\begin{array}{r}\text { D_Rabu_ } \\
\text { CS }\end{array}$ & $\begin{array}{r}\text { D_Rabu } \\
\text { Teller }\end{array}$ & $\begin{array}{r}\text { D_Kamis_- } \\
\text { CS }\end{array}$ & $\begin{array}{c}\text { D_Kamis_ } \\
\text { Teller }\end{array}$ \\
\hline N & & 9 & 9 & 10 & 10 \\
Poisson Parametera,b & Mean & 13,67 & 18,67 & 14,80 & 16,80 \\
& Absolute &, 427 &, 277 &, 300 &, 187 \\
Most Extreme & Positive &, 427 &, 277 &, 300 &, 100 \\
Differences & Negative &,- 228 &,- 200 &,- 290 &,- 187 \\
Kolmogorov-Smirnov Z & & 1,281 &, 830 &, 949 &, 592 \\
Asymp. Sig. (2-tailed) & &, 075 &, 495 &, 329 &, 875 \\
\hline
\end{tabular}

a. Test distribution is Poisson.

b. Calculated from data.

Dari tabel 3 menyatakan bahwa tingkat kedatangan di CS dan Teller mengikuti distribusi poisson karena nilai Asymp. Sig. (2-tailed) berturut-turut 0.75, 0.495, 0.329 dan $0.875>$ nilai $\alpha$ $=0.05$. Sehingga data tingkat kedatangan pada CS dan Teller yang digunakan dalam penelitian ini memenuhi asumsi dasar teori antrian. 
Tabel 4 : Pengujian Distribusi Eksponensial Pada Tingkat Pelayanan di CS dan Teller

One-Sample Kolmogorov-Smirnov Test

\begin{tabular}{|c|c|c|c|c|c|}
\hline & & P_Rabu_CS & $\begin{array}{c}\text { P_Rabu_T } \\
\text { eller }\end{array}$ & P_Kamis_CS & $\begin{array}{c}\text { P_Kamis } \\
\text { Teller }\end{array}$ \\
\hline \multicolumn{2}{|l|}{$\mathrm{N}$} & 9 & 9 & 10 & 10 \\
\hline Exponential & Mean & 26,67 & 2,11 & 26,90 & 2,10 \\
\hline \multirow{3}{*}{$\begin{array}{l}\text { Most Extreme } \\
\text { Differences }\end{array}$} & Absolute & ,451 & ,390 & ,427 & 414 \\
\hline & Positive & ,301 & ,241 & ,293 & ,240 \\
\hline & Negative &,- 451 &,- 390 &,- 427 &,- 414 \\
\hline \multicolumn{2}{|c|}{ Kolmogorov-Smirnov Z } & 1,354 & 1,170 & 1,352 & 1,310 \\
\hline \multicolumn{2}{|c|}{ Asymp. Sig. (2-tailed) } & ,051 & ,129 &, 052 & ,065 \\
\hline
\end{tabular}

a. Test Distribution is Exponential.

b. Calculated from data.

Dari Tabel 4 menyatakan bahwa Tingkat pelayanan mengikuti distribusi Eksponensial karena nilai Asymp. Sig. (2-tailed) berturut-turut 0.051, 0.129, 0.052 dan $0.065>$ nilai $\alpha=0.05$, sehingga data tingkat pelayanan pada CS dan Teller yang digunakan dalam penelitian ini memenuhi asusmsi dasar teori antrian.

\subsection{Tingkat Pelayanan Efektif}

Tingkat pelayanan efektif dihitung menggunakan rumus $J \times \mu$. Tingkat pelayanan efektif menurut asumsi dasar teori antrian harus memenuhi syarat dimana Tingkat pelayan efektif lebih besar dibandingkan dengan Tingkat kedatangan pelanggan, sehingga:

$$
J \mu>\lambda
$$

Tabel 5 : Pengujian Tingkat Pelayanan efektif pada tingkat kedatangan

\begin{tabular}{|c|c|c|c|c|}
\hline \multirow{2}{*}{ Hari } & \multicolumn{2}{|c|}{$\lambda$} & \multicolumn{2}{c|}{$j \mu$} \\
\cline { 2 - 5 } & CS & Teller & CS & Teller \\
\hline Rabu & 0,0563 & 0.0563 & 0,0754 & 0,9474 \\
\hline Kamis & 0,0588 & 0,0588 & 0,075 & 0,9524 \\
\hline
\end{tabular}




\subsection{Analisis Karakteristik Antrian Pembuatan KTM}

Dengan menggunakan rumus karakteristik model antrian (M/M/S)

$P_{0}=\frac{1}{\sum_{n=0}^{J-1} \frac{\left(\frac{\lambda_{1}}{\mu_{1}}\right)^{n}+\frac{\left(\frac{\lambda_{1}}{\mu_{1}}\right)^{J}}{J_{1} !\left(1-\frac{\lambda_{1}}{J \mu_{1}}\right)}}{}}$

$L_{a}=\frac{\left(\frac{\lambda_{1}}{\mu_{1}}\right)^{J_{1}+1}}{\left(J_{1}-1\right) !\left(J_{1}-\frac{\lambda_{1}}{\mu_{1}}\right)^{2}} P_{0}$

$L_{s}=L_{a}+\frac{\lambda_{1}}{\mu_{1}}$

$W_{a}=\frac{\left(\frac{\lambda_{1}}{\mu_{1}}\right)^{J_{1}+1}}{\lambda_{1}\left(J_{1}-1\right) !\left(J_{1}-\frac{\lambda_{1}}{\mu_{1}}\right)^{2}} P_{0}$

$W_{s}=W_{a}+\frac{1}{\mu_{1}}$

dengan $J$ adalah fasilitas pelayanan yang paralel, $P_{0}$ adalah rata-rata kedatangan pelanggan, adalah rata-rata pelayanan dalam satuan waktu, adalah tingkat kegunaan fasilitas pelayanan, adalah probabilitas tidak ada pelanggan, $L_{a}$ adalah rata-rata pelanggan dalam antrian, $L_{s}$ adalah rata-rata pelanggan dalam sistem, adalah waktu menunggu dalam antrian, dan adalah rata-rata waktu menunggu dalam sistem.

Sehingga dari hasil penghitungan tingakt kedatangan, tingkat pelayanan dan jumlah server yang tersedia pada masing-masing fase pada Tabel 1 dan Tabel 2, diperoleh:

Tabel 6 : Hasil analisis sistem antrian pembuatan KTM

\begin{tabular}{|c|c|c|c|c|}
\hline \multirow{2}{*}{ Karakteristik Antrian } & \multicolumn{2}{|c|}{ Rabu } & \multicolumn{2}{|c|}{ Kamis } \\
\hline & CS & Teller & CS & Teller \\
\hline Kemungkinan tidak ada & 0.145 atau & 0.8879 atau & 0.121 atau & 0.8837 atau \\
\hline antrian & $14,5 \%$ & $88,79 \%$ & $12,1 \%$ & $88,37 \%$ \\
\hline Rata-Rata Pelanggan Dalam & 1.8821 & 0.0004 & 2.4998 & 0.0005 \\
\hline Antrian $L_{a}$ & pelanggan & pelanggan & pelanggan & pelanggan \\
\hline Rata-Rata Jumlah Dalam & 3.3755 & 0.1193 & 4.0678 & 0.124 \\
\hline Sistem $L_{s}$ & pelanggan & pelanggan & pelanggan & pelanggan \\
\hline Rata-Rata Waktu Menungu & 33.5373 & 0.0075 & 42.4061 & 0.0081 \\
\hline Dalam Antrian $W_{a}$ & menit & menit & menit & menit \\
\hline Rata-Rata Waktu Menungu & 60.0625 & 2.1185 & 69.0728 & 2.108 \\
\hline Dalam Sistem $W_{s}$ & menit & menit & menit & menit \\
\hline Kemungkinan Menunggu $P_{t}$ & 0.6383 & 0.0067 & 0.6886 & 0.0071 \\
\hline
\end{tabular}




\subsection{Analisis Antrian Pembuatan KTM Dengan Program WinQSB}

Untuk membandingkan hasil yang diperoleh dengan penghitungan manual maka digunakan program WinQSB untuk penghitungan dengan menggunakan program.

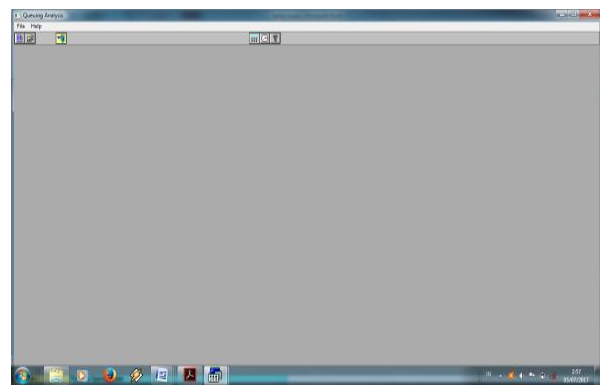

Gambar 1 : Tampilan utama

\begin{tabular}{|l|l|}
\hline Data Description & \multicolumn{1}{|c|}{ ENTRY } \\
\hline Number of servers & 2 \\
\hline Service rate (per server per minute) & 0.0375 \\
\hline Customer arrival rate (per minute) & 0.0588 \\
\hline Queue capacity (maximum waiting space) & M \\
\hline Customer population & M \\
\hline Busy server cost per minute & \\
\hline Idle server cost per minute & \\
\hline Customer waiting cost per minute & \\
\hline Customer being served cost per minute & \\
\hline Cost of customer being balked & \\
\hline Unit queue capacity cost & \\
\hline
\end{tabular}

Gambar 3 : Tampilan input

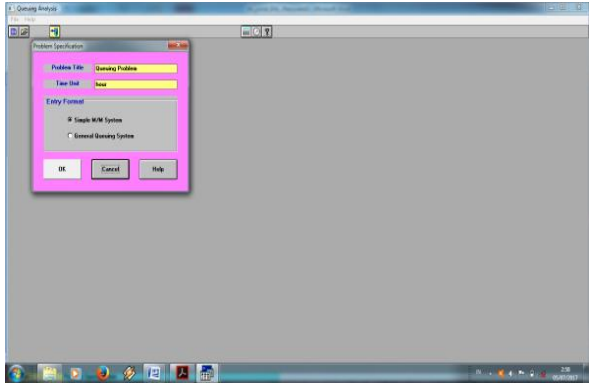

Gambar 2 : Tampilan spesifikasi masalah

\begin{tabular}{|c|c|c|}
\hline $05-09-2017$ & Performance Measure & Result \\
\hline 1 & System: H/H/2 & Fron Formula \\
\hline 2 & Customer arrival rate (lambda) per minute = & 0,0500 \\
\hline 3 & Service rate per server (mu) per minute = & 0,0375 \\
\hline 4 & Overall system effective arival rate per minute = & 0,0588 \\
\hline 5 & Overall system effective service rate per minute = & 0,0588 \\
\hline 6 & Overall sysstem utilization = & $78,4000 \%$ \\
\hline 7 & Ayerage number of customers in the system $(L)=$ & 4,0691 \\
\hline 8 & Average number of customers in the queue $(L q)=$ & 2,5011 \\
\hline 9 & Average number of customers in the queve for a busy system (Lb) = & 3,6296 \\
\hline 10 & Average time customer spends in the system [ $[W]=$ & 69,2022 minutes \\
\hline 11 & Average time customer spends in the queue $[W q]=$ & 42,5356 minutes \\
\hline 12 & Average time customer spends in the queue for a busy system ( $(w b)$ ] = & 61,7284 minutes \\
\hline 13 & The probability thal all servers are idle $\left(\mathrm{P}_{0}\right)=$ & $12,1076 \%$ \\
\hline 14 & The probability an arriving customer wails $(\mathrm{Pw}$ or $\mathrm{Pb})=$ & $68,9076 \%$ \\
\hline
\end{tabular}

Gambar 4 : Tampilan

\subsection{Pembahasan Analisis Model Antrian}

Sistem antrian yang terdapat pada BANK BNI UNTAD mengikuti model M/M/S, yaitu kedatangan mengikuti distribusi poisson dan waktu pelayanannya mengikuti distribusi eksponensial

\section{Banyaknya pelanggan dalam antrian}

Dari hasil yang didapatkan secara manual nilai $\left(L_{a}\right)$ pada hari rabu yaitu $L_{a}=1,8821$ pengantri pada loket CS dan $L_{a}=0,0004$ pengantri pada loket teller, sedangkan dari hasil yang didapatkan dengan menggunakan program adalah 1,8818 pelanggan pada server CS dan 0,0004 pelanggan pada server teller. Sedangkan pada hari kamis, dengan mengunakan cara manual nilai $L_{a}=2,4998$ pengantri pada loket CS dan $L_{a}=$ 0,0005 pengantri pada loket teller, sedangkan dari hasil yang didapatkan dengan menggunakan program WinQSB adalah 2,5011 pelanggan pada server CS dan 0,0005 pada server teller. Dari nilai yang didapatkan dengan cara manual maupun program mempunyai hasil yang sama 


\section{Banyaknya pelanggan dalam sistem $\left(l_{s}\right)$}

Dari hasil yang didapatkan secara manual, nilai $\left(l_{s}\right)$ pada hari rabu yaitu $l_{s}=3,3755+$ $0,1193=3.4948$ pada keseluruhan server, sedangkan pada hari kamis yaitu $l_{s}=$ $4,0678+0,124=4,1918$ pada keseluruhan server. Sedangkan dari hasil yang didapatkan dengan menggunakan program WinQSB pada hari rabu adalah $l_{s}=3,4944$ dan pada hari kamis adalah $l_{s}=4,193$. Sehingga banyaknya pelanggan dalam sistem sama atau tidak jauh berbeda antara penghitungan manual dengan penghitungan menggunakan program WinQSB.

\section{Waktu tunggu pelanggan dalam antrian $\left(W_{a}\right)$}

Dari hasil yang didapatkan secara manual, nilai $\left(W_{a}\right)$ pada hari rabu yaitu $\left(W_{a}\right)=$ 33,5373 menit pada server CS dan $\left(W_{a}\right)=0,0075$ menit pada server teller, sedangkan pada hari kamis $\left(W_{a}\right)=42,4061$ menit pada server CS dan $\left(W_{a}\right)=0,0081$ menit pada server teller. Sedangkan dari hasil yang didapatkan dengan menggunakan program WinQSB pada hari rabu adalah 33,4238 menit pada server CS dan 00075 menit pada serverteller, sedangkan pada hari kamis 42,5356 menit pada serverCS dan 0,008 menit pada server teller. Sehingga waktu tunggu dalam antrian sama atau tidak jauh berbeda antara penghitungan manual dengan penghitungan menggunakan program WinQSB.

\section{Waktu tunggu pelanggan dalam sistem $\left(W_{s}\right)$}

Dari hasil yang didapatkan, nilai $\left(W_{S}\right)$ pada rabu yaitu $\left(W_{s}\right)=60,0625+2,1185=$ 62,181 menit, sedangkan pada hari kamis yaitu $\left(W_{S}\right)=69,0728+2,108=71,1808$ menit. Sedangkan dari hasil yang didapatkan dengan menggunakan program WinQSB pada hari rabu adalah $\left(W_{s}\right)=62,1675$ dan pada hari kamis adalah $\left(W_{s}\right)=71,3102$. Sehingga waktu tunggu pelanggan dalam sistem sama atau tidak jauh berbeda antara penghitungan manual dengan penghitungan menggunakan program WinQSB.

\section{KESIMPULAN}

Berdasarkan hasil analisis antrian pada BANK BNI UNTAD Palu, dapat diambil kesimpulan sebagai berikut :

1. Sistem antrian di BANK BNI UNTAD Kota Palu Termasuk kedalam model multi phase (M/M/S) atau sistem antrian dengan serve ryang disusun secara berurutan.

2. Pelayanan di BANK BNI UNTAD Palu masih dalam kondisi stabil dilihat dari ukuran steady state yaitu sebesar 0,7957, 0,784, 0,0593 dan 0,0617.

3. Banyaknya pelanggan dalam antrian pada hari rabu adalah 3 pelanggan di CS dan 1 pelanggan di teller. Sedangkan pada hari kamis adalah 2 pelanggan di CS dan1 pelanggan di teller. 
4. Banyaknya pelanggan dalam sistem pada hari rabu dan kamis adalah sama yaitu 4 pelanggan.

5. Rata-rata waktu yang digunakan pelanggan dalam antrian untuk mendapatkan pelayanan pada hari rabu adalalah 45,3514 dan 0.0076 . Sedangkan pada hari kamis adalah 42,4061 menit dan 0,0081 menit.

6. Rata-rata waktu yang digunakan dalam sistem pada hari rabu dan kamis adalah74,1952 menit dan 71,1808 menit.

\section{DAFTAR PUSTAKA}

[1]. Handoko, H. Manajemen. Edisi Kedua, Yogyakarta: BPFE-Yogyakarta, 2000.

[2]. Heizer, J dan Render. B. Operation Management, Terjemahan oleh Dwianoegrawati Setyoningsih dan Indra Almahdy, Edisi 7, Buku I, Jakarta: Salemba Empat, 2006.

[3]. Ma'arif dan Tanjung. Mananajemen Produksi dan Operasi, Edisi Revisi, Jakarta: Fakultas Ekonomi Universitas Jakarta, 2003.

[4]. Supranto, J. Riset OperasiUntuk Pengambilan Keputusan, Jakarta: UI-Press, 1988.

[5]. Suyadi. Riset Operasi dan Ekonofisika, Jakarta : Bumi Akasara, 2004.

[6]. Taha, A.H, Riset Operasi. Jakarta : Binarupa Aksara, 1996.

[7] Tampubolon, M.P. Manajemen Operasional, Jakarta: PT, Ghalia Indonesia, 2004. 